\title{
Seasonal and algal diet-driven patterns of the digestive microbiota of the European abalone Haliotis tuberculata, a generalist marine herbivore
}

Angélique Gobet ${ }^{1 *}$ (D), Laëtitia Mest ${ }^{1}$, Morgan Perennou ${ }^{2}$, Simon M Dittami ${ }^{1}$, Claire Caralp ${ }^{3}$, Céline Coulombet ${ }^{4}$, Sylvain Huchette ${ }^{4}$, Sabine Roussel ${ }^{3}$, Gurvan Michel ${ }^{1 *}$ and Catherine Leblanc ${ }^{1 *}$

\begin{abstract}
Background: Holobionts have a digestive microbiota with catabolic abilities allowing the degradation of complex dietary compounds for the host. In terrestrial herbivores, the digestive microbiota is known to degrade complex polysaccharides from land plants while in marine herbivores, the digestive microbiota is poorly characterized. Most of the latter are generalists and consume red, green, and brown macroalgae, three distinct lineages characterized by a specific composition in complex polysaccharides, which represent half of their biomass. Subsequently, each macroalga features a specific epiphytic microbiota, and the digestive microbiota of marine herbivores is expected to vary with a monospecific algal diet. We investigated the effect of four monospecific diets (Palmaria palmata, U/va lactuca, Saccharina latissima, Laminaria digitata) on the composition and specificity of the digestive microbiota of a generalist marine herbivore, the abalone, farmed in a temperate coastal area over a year. The microbiota from the abalone digestive gland was sampled every 2 months and explored using metabarcoding.

Results: Diversity and multivariate analyses showed that patterns of the microbiota were significantly linked to seasonal variations of contextual parameters but not directly to a specific algal diet. Three core genera: Psychrilyobacter, Mycoplasma, and Vibrio constantly dominated the microbiota in the abalone digestive gland. Additionally, a less abundant and diet-specific core microbiota featured genera representing aerobic primary degraders of algal polysaccharides.

Conclusions: This study highlights the establishment of a persistent core microbiota in the digestive gland of the abalone since its juvenile state and the presence of a less abundant and diet-specific core community. While composed of different microbial taxa compared to terrestrial herbivores, the digestive gland constitutes a particular niche in the abalone holobiont, where bacteria (i) may cooperate to degrade algal polysaccharides to products assimilable by the host or (ii) may have acquired these functions through gene transfer from the aerobic algal microbiota.
\end{abstract}

Keywords: Microbe-host interactions, Digestive microbiota, Abalone, Macroalgae, Holobiont

\footnotetext{
* Correspondence: angeliquegobet@gmail.com; gurvan.michel@sb-roscoff.fr; catherine.leblanc@sb-roscoff.fr

'Sorbonne Universités, UPMC Université Paris 06, CNRS, UMR 8227, Integrative Biology of Marine Models, Station Biologique de Roscoff, CS 90074, F-29688 Roscoff Cedex, France

Full list of author information is available at the end of the article
} 


\section{Background}

A holobiont is defined as a meta-organism consisting of a host (e.g., animal, plant, alga) and its associated microbiota. A healthy holobiont is considered to have a resilient microbiota, which may adapt and respond differently depending on external disturbances [1]. The importance of the holobiont concept is increasingly coming into the focus of ecological and clinical research due to the major role of, for instance, digestive microbiota in host digestion, host health, and host development [2-5]. For instance, the ruminant gastro-intestinal tract contains specific bacterial groups able to degrade complex plant cell-wall polysaccharides such as cellulose, hemicelluloses, and pectins, allowing polymer assimilation during digestion and accounting for $70 \%$ of the host energy intake [6].

In the marine environment, herbivores feed on macroalgae which live associated with an epiphytic microbiota. These play major roles in health and physiology of macroalgae [7], such as host adaptation to varying environmental conditions [8], bacteria-induced morphogenesis [9, 10], or via their antifouling activity [11]. Reciprocally, algal biomass constitutes a large choice of carbon sources for heterotrophic bacteria, especially polysaccharides, which represent about $50 \%$ of the algal dry weight. Red, green, and brown algae each have a different polysaccharide composition and most of the macroalgal polysaccharides are absent from land plants $[12,13]$. To feed on seaweeds, marine heterotrophic bacteria have evolved specific enzymes such as agarases, carrageenases, fucoidanases, or ulvan lyases [14, 15]. Therefore, the macroalgal microbiota is significantly enriched in algal polysaccharide-degrading bacteria (mainly Bacteroidetes and Gammaproteobacteria) in comparison to the water column [16]. Notably, the macroalga-associated bacterial community differs between red, green, and brown algae [17-20].

Most marine herbivores are generalists, meaning they are able to feed on the three macroalgal lineages, but only few studies have been performed on digestive microbiota in marine herbivores. Bacteria have been shown to help degrade macroalgal polysaccharides in the sea hare Aplysia spp., the snail Tegula funebralis, the limpet Patella pellucida, and the iguana Amblyrhynchus cristatus [21-24], but these studies considered neither different diet types nor seasonality. The abalone, a gastropod of high economic interest especially in China, Korea, South Africa, and Chile [25, 26], is also a generalist herbivore [27], but its digestive enzymes are not sufficient for macroalgal polysaccharide degradation [28]. This makes the abalone an interesting model to investigate the composition, seasonality, and role of the digestive microbiota associated with several diet types.
We selected four local monospecific macroalgal diets based on abalone food preferences, nutritional quality, and on their biochemical composition: the brown algae Saccharina latissima and Laminaria digitata, the red alga Palmaria palmata, and the green alga Ulva lactuca. We determined the composition of the microbiota from the abalone digestive gland, and we tested the following hypotheses: (i) the marine herbivore gastrointestinal tract offers a specific niche for specific marine bacteria, (ii) algal diet, host characteristics, and time influence microbiota composition and fluctuations, (iii) specific microbial groups are associated with the digestion of a monospecific macroalgal diet, allowing for the abalone' polyphagy.

\section{Results}

Here, we investigate the impact of four monospecific algal diets on the abalone digestive microbial community. For each of the four algal diets, abalone reared in 3 independent cages were sampled at 6 time points over a year and the abalone digestive microbiota from the resulting 72 samples was further studied through a metabarcoding analysis.

\section{Diet-specific seasonal diversity patterns of the digestive microbial community}

Operational taxonomic unit (OTU, defined at 97\% sequence identity) richness and evenness of the digestive microbiota were investigated for each algal treatment and sampling date. When all sampling dates were pooled, alpha-diversity did not significantly vary between algal diets on average, but when algal diets were considered separately, alpha-diversity followed different seasonal patterns. In the case of the L. digitata diet, samples from colder months (February-April 2012, January 2013) presented significantly lower alpha-diversity indices on average than those from warmer months (Wilcoxon test, $P<0.001$, Additional file 1: Figure S1, Additional file 2: Table S1). In the case of the $S$. latissima and $U$. lactuca diets, diversity increased over the year and diversity seemed stable with time for the P. palmata treatment.

Similarly, when the structure of the bacterial community associated with the abalone digestive gland was investigated at the OTU level (Fig. 1), diet had only a minor impact on the bacterial community (ANOSIM, $R$ $=0.05, P<0.01$, Additional file 3: Table S2). However, there was a clear grouping of samples according to season and date $(R=0.36$ and $R=0.43$, respectively, $P<$ $0.01)$. When considering each monospecific diet individually, bacterial communities associated with $P$. palmata digestion were more different between sampling dates than between the cage triplicates (ANOSIM: $R=$ 0.41-1). Bacterial communities associated with the $U$. lactuca diet showed noticeable differences between the 

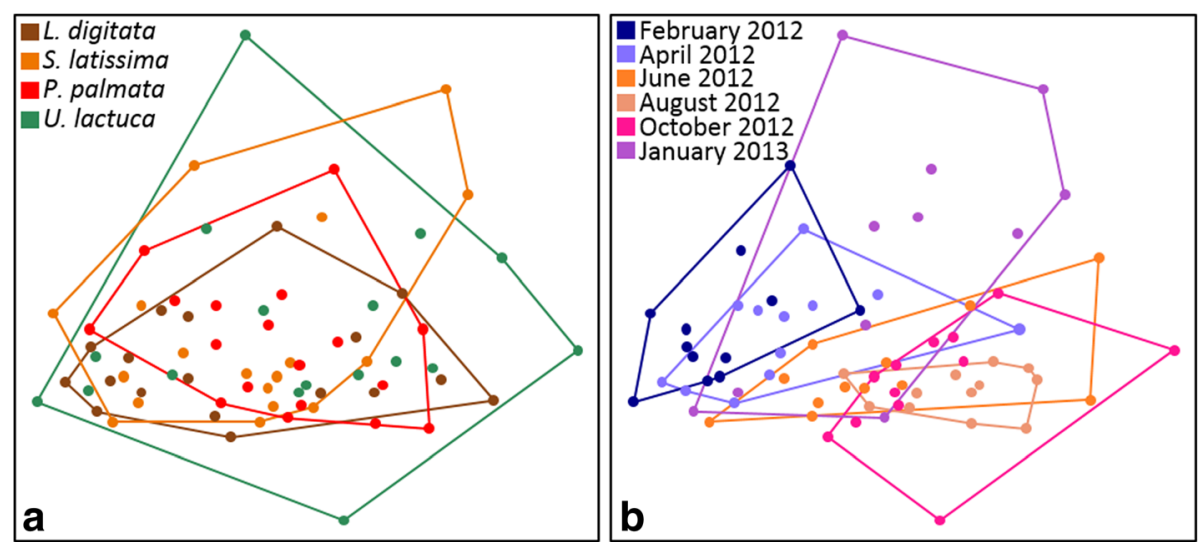

Fig. 1 Community structure of the digestive microbiota of the abalone over 1 year. Samples were grouped a posteriori according to one of the four monospecific algal diets (a) or a sampling date (b). The Bray-Curtis dissimilarity index was calculated after Hellinger transformation of the metabarcoding data set at the OTU level. The low stress value of $18 \%$ validates the goodness-of-fit of the two-dimensional representation compared with the original matrix. Significance between groupings of samples according to algal diet, sampling date, or season was tested using ANOSIM (Additional file 3: Table S2)

beginning of the experiment (February-April 2012) and January $2013(R=0.83)$. Seasonal effects were stronger for the $L$. digitata diet than for the other diets, with samples from colder months separated from those from warmer months. For the microbial communities associated with the S. latissima diet, bacterial communities sampled in January 2013 were significantly different from other dates $(R>0.8, P<0.001)$. Overall, diversity patterns of the abalone digestive microbiota showed seasonal patterns specific to a given monospecific diet.

\section{Fluctuations of OTUs associated with each monospecific algal diet}

The distribution of OTUs linked to a monospecific diet was investigated by measuring proportions of OTUs shared between two consecutive sampling dates. For instance, in the digestive microbiota associated with the P. palmata diet, there were $29-40 \%$ OTUs common to abalone sampled in February 2012 and those sampled in April 2012, meaning that there were about $60-71 \%$ new OTUs after 2 months of monospecific diet (Additional file 1: Figure S2A). Over the year, the proportions of OTUs common to two consecutive sampling dates varied between 16-59\%, $18-70 \%, 23-61 \%$, and $10-71 \%$ for the P. palmata, U. lactuca, L. digitata, and S. latissima diets, respectively. These common OTUs, however, accounted for $40-99 \%$ of the sequence reads (Additional file 1: Figure S2). About 3\% OTUs were present the whole year for each monospecific diet and corresponded to a large proportion of sequence reads (from $88-97 \%$ in each cage). Altogether, this indicates that the rarest OTUs fluctuate with time while the most abundant OTUs remain in the digestive gland during the year, indicating the presence of a dominant core microbial community associated with each algal diet.
Few bacterial genera dominate the core digestive microbiota at the start of the experiment

In February 2012, after abalone had not been fed for a week, the most abundant phyla were Fusobacteria, Tenericutes, and Gammaproteobacteria (average of 72, 14 , and $9 \%$ of all sequence reads per cage, respectively, Additional file 1: Figure S3). The phylum Fusobacteria was mostly composed of the genus Psychrilyobacter (99.9\% of sequences in the phylum; $31 \%$ to $94 \%$ of all sequence reads per cage) and the phylum Tenericutes of Mycoplasma (99.9\% of sequences in the phylum; 3-32\% of all sequence reads per cage). The third most abundant taxonomic group, the class Gammaproteobacteria, was composed mainly of Vibrio (68\% of sequence reads in the phylum; $1-23 \%$ of all sequence reads per sample). Other genera present in all cages represented $2 \%$ or less of the sequence reads per cage (Fig. 2). These global patterns validate the dominance of few genera in the abalone digestive microbiota at the starting point of the experiment.

\section{Composition and seasonal and diet-driven fluctuations of the core digestive microbiota}

Over a year, 10-15\% OTUs were shared by the 4 monospecific diets. For all sampling dates pooled per algal diet, 22\% of the OTUs of the whole community corresponded to a core community shared by the 4 diets (Fig. 3). To better understand the potential functioning of this core community, we focused on temporal fluctuations of these OTUs constantly found in the digestive microbiota. We considered as the core microbiota only the OTUs occurring in all samples, considering each of the four algal diets, for each cage triplicate and during the whole year. Six OTUs belonging to the classes Fusobacteriia, Gammaproteobacteria, and Mollicutes fit this definition: one Psychrilyobacter OTU, two Vibrio OTUs, two Mycoplasma OTUs, and an unclassified OTU. 


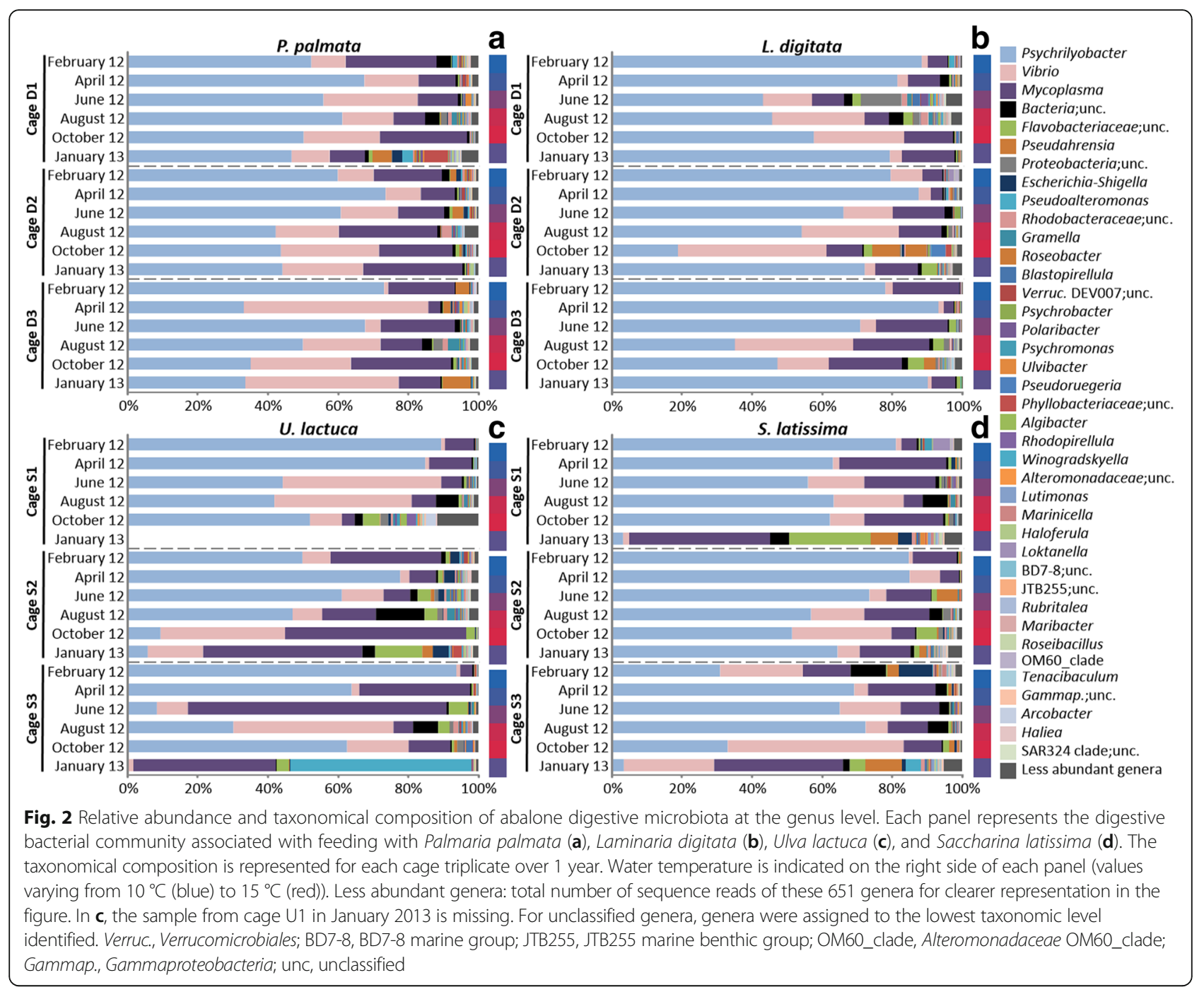

In terms of sequence read abundance, these six OTUs represented about $86 \%$ of the microbiota (Fig. 4), although relative contribution of each of these OTUs was variable (Fig. 2). Apart from these 3 dominating core genera, 5 to 8 additional genera belonged to a core microbiota specific to each algal diet and they represented lower relative abundances of OTUs, ranging from 0.001 to $24.5 \%$ of sequence reads per cage (Fig. 4). Some OTUs belonged to genera found with at least two monospecific diets: Lutimonas, Psychromonas, Roseobacter, and four unclassified genera. Other genera were specific to a given diet. Polaribacter and Pseudahrensia were associated with the P. palmata diet, Escherichia-Shigella to the $U$. lactuca diet, Roseibacillus to the $L$. digitata diet, and Ulvibacter was associated with the S. latissima diet (Fig. 4).

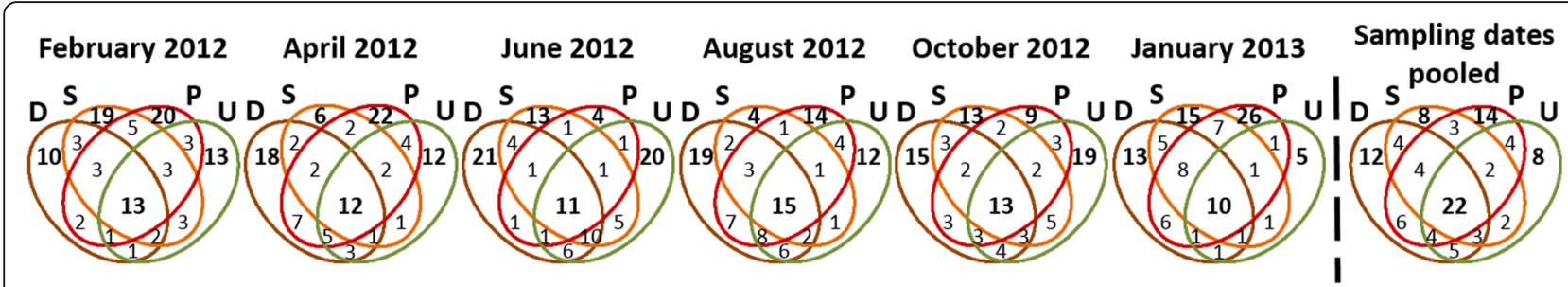

Fig. 3 Comparison of the microbial OTU composition associated with the four algal diets. Comparisons are described by proportions of shared or unique OTUs and were made for each sampling date from February 2012 to January 2013 and for the six sampling dates pooled according to diet. D, L. digitata; S, S. latissima; P, P. palmata; U, U. lactuca 


\section{P. palmata}

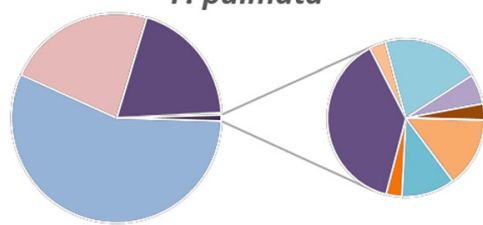

U. Iactuca

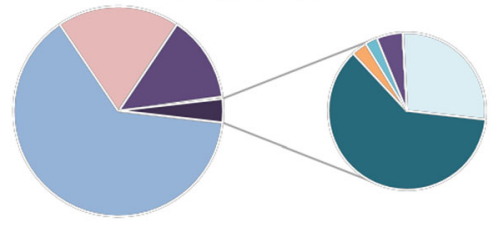

L. digitata

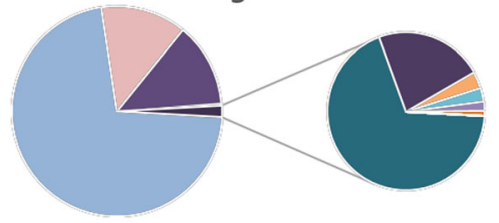

Legend

S. latissima

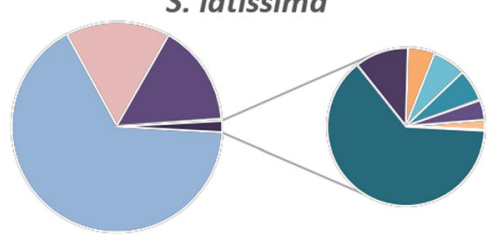

\begin{tabular}{|l|}
\hline \multicolumn{2}{|l|}{ Psychrilyobacter } \\
Vibrio Core microbiota \\
Mycoplasma to all diets \\
Bacteria; unclassified \\
\hline Flavobacteriaceae; unclassified \\
Roseobacter \\
Lutimonas
\end{tabular}

BD7-8_marine_group;unclassified

Roseibacillus

Psychromonas

Ulvibacter

Rhodobacteraceae; unclassified

Desulfobulbaceae; unclassified

Polaribacter

Pseudahrensia

Gammaproteobacteria; unclassified

Escherichia-Shigella

Fig. 4 Composition of the digestive core microbiota at the genus level associated with a monospecific diet. Pie charts on the left represent proportions of sequence read abundances, at the genus level, representative of the core microbiota of a monospecific diet. Pie charts on the right represent detailed proportions of less abundant genera representative of the core microbiota of a monospecific diet

\section{Algal polysaccharide digestion potential of the core digestive microbiota}

To further explore the potential role of Psychrilyobacter, Vibrio, and Mycoplasma in algal digestion, we compared their carbohydrate-active enzymes (CAZymes) and sulfatase contents to that of Zobellia galactanivorans Dsij ${ }^{\mathrm{T}}$, a model bacterium for the bioconversion of algal polysaccharides [29]. This was done based on the public CAZy and SulfAtlas databases (Table 1, Additional file 4: Table S3 and Additional file 5: Table S4). This approach is of course limited by the availability of genomes of some genera in public databases. Still, similar results were found in several available genomes of a given genus and are likely to reflect at least some functions present

Table 1 Total number of putative glycoside hydrolase $(\mathrm{GH})$, polysaccharide lyase (PL), and sulfatase genes in selected genomes

\begin{tabular}{|c|c|c|c|c|}
\hline & $\mathrm{GH}^{\mathrm{a}}$ & $\mathrm{PL}^{\mathrm{a}}$ & Sulfatases & $\overline{\text { References }}$ \\
\hline Psychrilyobacter atlanticus DSM 19335 & $\begin{array}{l}13^{b} \\
23^{c}\end{array}$ & $\begin{array}{l}0 \\
0\end{array}$ & $\begin{array}{l}0 \\
2\end{array}$ & [32] \\
\hline 127 Vibrio genomes & $\begin{array}{l}9-27 \\
22-70\end{array}$ & $\begin{array}{l}0-5 \\
0-21\end{array}$ & $\begin{array}{l}0-5 \\
0-9\end{array}$ & {$[33,34]$} \\
\hline 111 Mycoplasma genomes & $\begin{array}{l}0-6 \\
0-12\end{array}$ & $\begin{array}{l}0-1 \\
0-1\end{array}$ & $\begin{array}{l}0 \\
0\end{array}$ & {$[31]$} \\
\hline Z. galactanivorans Dsij ${ }^{\top}$ & $\begin{array}{l}44 \\
141\end{array}$ & $\begin{array}{l}8 \\
15\end{array}$ & $\begin{array}{l}17 \\
71\end{array}$ & {$[27]$} \\
\hline
\end{tabular}

This table also contains total number of GH, PL, and sulfatase families in selected genomes from the three genera of the core digestive microbiota of the abalone and of Zobellia galactanivorans DsijT, a model bacterium for algal polysaccharide degradation. For more details on the CAZyme and sulfatase content, see Additional file 4: Table S3 and Additional file 5: Table S4

${ }^{\mathrm{a} C A Z y m e ~ c l a s s}$

${ }^{\mathrm{b}}$ Total number of CAZyme or sulfatase families in the given class

'Total number of CAZyme or sulfatase genes in the given class

Z. galactanivorans Zobellia galactanivorans; GH glycoside hydrolase, PL polysaccharide lyase. Data retrieved from the CAZy and SulfAtlas databases (www.cazy.org, [35], http://abims.sb-roscoff.fr/sulfatlas/, [36]) 
in abalone digestive microbiota. As there was no Psychrilyobacter genome available in the CAZy and SulfAtlas databases, we manually annotated the CAZyme- and sulfatase-coding sequences in the only genome of the genus available to date in NCBI Genome [30], i.e., that of Psychrilyobacter atlanticus DSM 19335, a strictly anaerobic bacterium isolated from marine sediment [31]. Compared to the genome of Z. galactanivorans Dsii ${ }^{\mathrm{T}}$, the genome of $P$. atlanticus DSM 19335, contains far fewer GHs and sulfatases as well as no polysaccharide lyases (Table 1, Additional file 5: Table S4). These genes are likely to enable the degradation of extracellular oligosaccharides, but not the degradation of complex algal polysaccharides (Additional file 5: Table S4). To evaluate the ability of Vibrio to degrade algal polysaccharides in the digestive gland, we examined the CAZyme and sulfatase content in the 127 Vibrio genomes available in the CAZy and SulfAtlas databases to date (Additional file 4: Table S3 and Additional file 5: Table S4). The 127 genomes present lower numbers of CAZyme and sulfatase families than the Z. galactanivorans genome (Table 1, Additional file 4: Table S3 and Additional file 5: Table S4). However, all examined Vibrio genomes contain at least one enzyme involved in chitin and/or cellulose metabolism (GH9, GH18, GH19, GH20, GH94 families) and at least one enzyme degrading extracellular oligosaccharides. Some Vibrio genomes such as $V$. crassostreae 9CS106, $V$. breoganii FF50, $V$. owensii XSBZ03, V. halioticoli NBRC 102217, three strains of $V$. alginolyticus (ATCC 33787, K08M4, and ATCC 17749), and $V$. harveyi also are able to degrade the red algal polysaccharide agarose (aga genes from families GH16, GH50), laminarin (lam genes family GH3), and/or alginate (alyA genes from families PL6, PL7, PL15, PL17) from brown algae (Additional file 4: Table S3, [32]). For Mycoplasma, we examined 111 genomes, which show poor capacities to degrade complex carbohydrates and no ability to degrade algal polysaccharides (Additional file 5 : Table S4, [33]).

Among the five to eight additional core genera per diet, we only found genomes of the genera Roseobacter, Psychromonas (two genomes each), and Polaribacter (six genome) in the CAZy and SulfAtlas databases, and we searched for their algal polysaccharide degradation abilities (Fig. 4, Additional file 4: Table S3). Roseobacter (a genus only found associated with the two brown algal diets) shows a low capacity to degrade algal polysaccharides with only some secreted exo-glycosidases. Psychromonas (associated with the $L$. digitata and P. palmata diets) is likely able to degrade brown algal polysaccharides with several enzymes acting on extracellular oligosaccharides and a laminarinase from family GH16, but there was no sign of enzymes acting on red algal polysaccharides. All six genomes of the genus Polaribacter, associated with the
P. palmata diet, contain enzymes acting on red algal polysaccharides, such as agar or porphyran (e.g., enzymes from families GH16, GH86, or GH117), or more specifically on carrageenans $(P$. sp. KT25b contains 2 iota-carrageenases from family GH82). Most of these genomes also encode enzymes able to degrade major algal cell wall polymers such as cellulose and hemicelluloses (e.g., presence of an endo-1,4- $\beta$-xylanase from family GH10, a GH39 xylosidase, and enzymes from families GH43, GH51, GH53, GH115, GH127).

\section{Ecological patterns of the whole and the core digestive microbiota}

Potential relationships between the structure of the digestive microbiota and contextual parameters were investigated by applying a multivariate variation partitioning approach. Biological variation of the digestive microbiota was significantly linked to the pure effect of diet composition (adjusted $R^{2}=5.4 \%, P<0.05$ ). Sampling dates, the combined effect of abalone and algal composition, the combined effect of algal composition and sampling dates, and the effect of the three explanatory variables together also explained the structuring of the microbial community (adj. $R^{2}=2.2 \%, 7.4 \%, 12.2 \%, 2.5 \%$, respectively, Additional file 1: Figure S4). Overall, $30.8 \%$ of the biological variation of the microbial community structure was explained by abalone characteristics, algal composition, and sampling dates $(P<0.001$, Additional file 1 : Figure S4). The remaining $69.2 \%$ of the biological variation not explained by the selected model suggests the effect of additional variables not included in this analysis. Still, our analysis clearly demonstrates a relationship between algal diet composition, sampling dates, and the structure of the digestive microbiota.

Pairwise comparisons between individual bacterial genera from the core digestive microbiota (Fig. 4) and contextual parameters showed specific ecological patterns. The genera Psychrilyobacter, an unclassified Flavobacteriaceae, and Ulvibacter followed similar patterns. They increased in relative OTU abundances with a decreasing content in mostly the same algal biochemical compounds and with increasing abalone digestive gland weight. Mycoplasma also showed similar patterns related to abalone characteristics. OTU proportions of Vibrio, Psychromonas, an unclassified Rhodobacteraceae, Polaribacter, and Pseudahrensia likely increased with increasing temperature and no significant relationships were found with other parameters (Fig. 5).

\section{Discussion}

In holobionts, the digestive enzymes of the host do not allow a complete degradation of complex polysaccharides which suggests the importance of a digestive microbiota. Marine generalist herbivores such as the abalone face the 


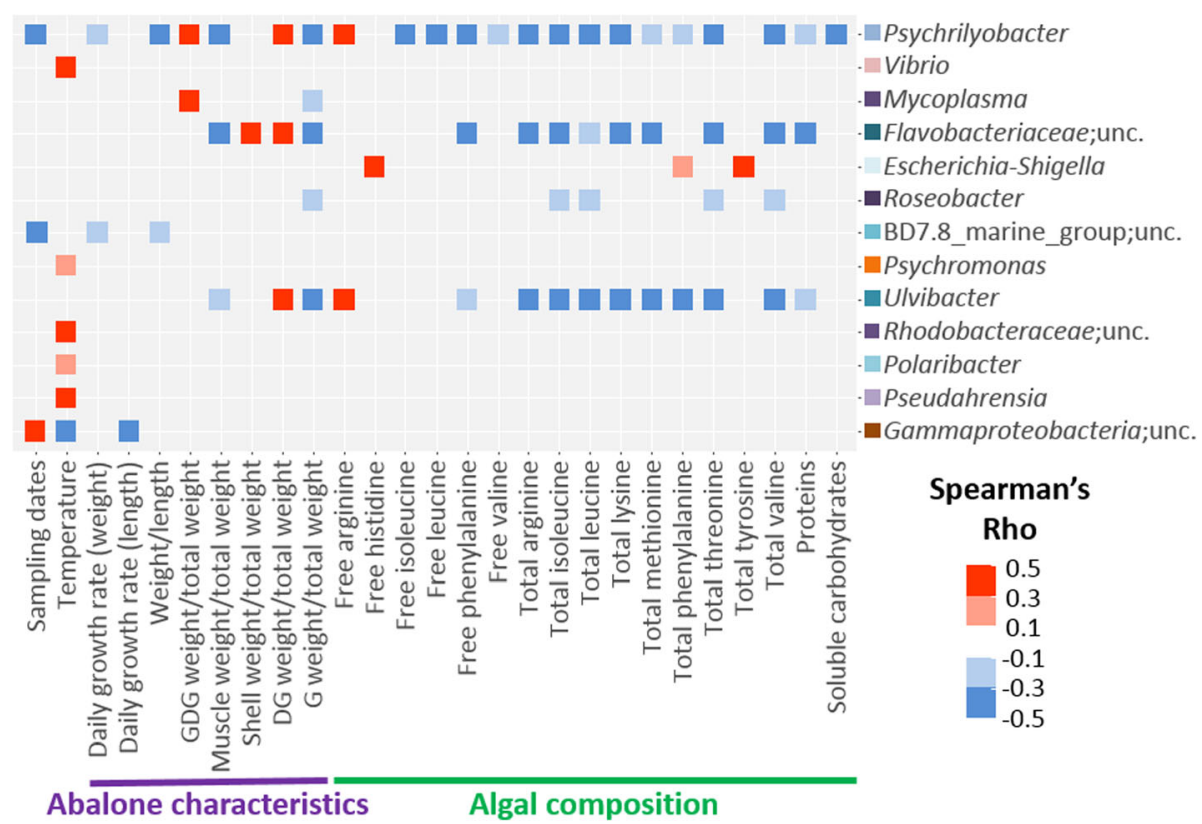

Fig. 5 Pairwise comparison between genera of the core microbiota and contextual parameters. Pairwise comparisons were measured by Spearman correlation. The core microbial genera were ordered according to sequence read abundance; with Psychrilyobacter being the most abundant group. The strength of the correlation is indicated by a heatmap colored from red to blue. The horizontal axis corresponds to sampling dates, temperature, abalone characteristics and algal diet composition. Only significant correlations after application of the Benjamini-Hochberg correction for multiple testing were represented. GDG, gonado-digestive gland; DG, digestive gland; G, gonad. Unc, unclassified

challenge of feeding on the three marine macroalgal lineages, which are composed of different combinations of neutral, carboxylated or carboxylic-bearing and sulfated polysaccharides [12]. Here, we determine the taxonomic composition and the seasonal structure of the digestive microbiota of the abalone holobiont, a marine gastropod grown in natural conditions on four monospecific diets over a year. This long-term study revealed that (i) the marine herbivore gastrointestinal tract offers a specific niche for a dominant core microbiota, constitutive of the abalone holobiont, (ii) microbiota composition and fluctuations are correlated to seasonal variations of contextual parameters, and that (iii) few specific microbial groups were associated with a monospecific macroalgal diet.

\section{The abalone holobiont features a characteristic core microbiota well established in the digestive gland}

Three bacterial core genera, the Fusobacteria Psychrilyobacter, the Tenericutes Mycoplasma, and the Gammaproteobacteria Vibrio, dominated the abalone digestive microbiota for the whole year and for each of the monospecific algal diet. Bacteria from these genera are known as obligate (Psychrilyobacter) or facultative anaerobes (Mycoplasma and Vibrio) [31, 34, 35]. This unexpected dominance of a core microbiota through the entire year may not only be due to the initial diet composition but also to gut morphology and its physicochemical and biochemical conditions [2]. The abalone gastrointestinal tract offers stable environmental conditions, which are microaerophilic or anaerobic, with an acidic $\mathrm{pH}$ of 5.3-6 in the crop and the digestive gland [36,37]. It has been previously shown that an acidic $\mathrm{pH}$ together with the presence of volatile fatty acid in the rumen is toxic for some bacteria [38] and thus likely to select for bacteria adapted to such conditions. Indeed, anaerobic bacteria from the classes Fusobacteriia and Mollicutes are only rarely found in coastal waters or associated with macroalgae [39-41]. However, these bacterial groups seem rather typical of digestive organs of marine holobionts as they are found in the sea squirt Ciona intestinalis, the limpet Patella pellucida, and marine carnivores [21, 42, 43]. Members of Vibrio are well known as pathogen of animals, and it is the most common bacterial genus in guts of marine animals such as the intestinal mucosa of marine fishes [35, 44-46]. Vibrio is also found associated with algae such as Ascophyllum nodosum, S. latissima, and decomposing fronds of Laminaria spp. [11, 16, 47]. Other gut microbiota also contain dominant core communities, e.g., the human gut microbiota is dominated by anaerobic bacteria belonging to Firmicutes and Bacteroidetes, representing more than $98 \%$ of $16 \mathrm{~S}$ rRNA sequences, with few other anaerobes from other phyla and only a couple of aerobic Actinobacteria [6, 48, 49]. Gut microbiota of terrestrial gastropods are also dominated by a low diversity of anaerobes, including the 
Gammaproteobacteria Enterobacter, some Firmicutes, and Bacteroidetes [50, 51]. Therefore, the dominant digestive microbiota constitutive of the abalone holobiont comprises bacterial taxa typically found in marine environments and these taxa are not dominant in the gut of terrestrial holobionts.

Additionally, a less abundant core microbiota was specific to at least a monospecific diet and contained aerobic genera: the Flavobacteriia Lutimonas, Ulvibacter, and Polaribacter; the Alphaproteobacteria Roseobacter and Pseudahrensia; the Gammaproteobacteria Psychromonas and Escherichia-Shigella; and the Verrucomicrobia Roseibacillus [52-59]. Notably, all members of this diet-specific and less abundant core microbiota, with the exception of Pseudahrensia, were identified during a phytoplankton bloom in temperate coastal waters in the North Sea [41]. This suggests that these bacteria may not only be part of the epiphytic algal diet microbiota but could also be part of the bacterioplankton and be ingested along with the alga. For instance, members of the genera, Roseobacter, Ulvibacter, and Roseibacillus, were previously isolated from green and brown algae, and Roseobacter was found associated with the red alga Gracilaria vermiculophylla [19, 53, 55, 58]. Strains of Polaribacter and Psychromonas were previously found associated with Laminaria sp. and S. latissima, and both genera have members that can degrade red algal polysaccharides [54, 57, 60, 61]. Lutimonas and Pseudahrensia, however, were found only in marine invertebrates or seawater but not associated with algae [52, 56, 62-64]. The occurrence and maintenance over time of few diet- or plankton-derived specific bacteria suggests a selectivity of some genera, which could participate to the global functioning of the digestive gland in abalone. The remaining OTUs that are not part of the core microbiota are transient bacteria and represent a smaller fraction of the digestive microbiota over the year (up to $14 \%$ of sequence reads per cage). These rarer bacteria are probably ingested along with the algal diet and have either (i) died and left DNA remains in the digestive gland or (ii) survived the selection pressure and may participate in the algal recycling in the abalone digestive gland [65].

Such organization of the microbiota in abalone digestive gland consists of two groups of bacteria: one resident group comprising the dominant bacteria and another one comprising the less abundant diet-specific bacteria and rarer bacteria which are transient over the year. Dominance of few bacterial taxa in the digestive microbiota may contribute to holobiont health and, as proposed in the case of human gut microbiota, such stability may allow for a certain resiliency in response to invasive pathogens or other exogenous microbes $[1,3]$. Further, the presence of less abundant taxa may also participate in abalone holobiont health. Previous studies on human lung- or plant-associated microbes showed that rare species were also involved in host protection against pathogens [66, 67]. On another hand, in a case of a disturbance strong enough to destabilize the core microbiota, these rarer OTUs may become more abundant and fill the niche previously occupied by the dominant bacterial community. They can either fill the same functions as the core microbiota and contribute to holobiont health or become pathogens $[3,68]$.

\section{Seasonal variations of abalone digestive microbiota}

Our experiment was carried out in an abalone farm located at the French Brittany coast where waters are impacted by seasonal variations specific to this permanently mixed ecosystem $[69,70]$. These temperate coastal waters were coldest in February-April 2012 and January $2013\left(10-11.5^{\circ} \mathrm{C}\right)$ and warmest from June to October 2012 (12.5-15 ${ }^{\circ} \mathrm{C}$, Additional file 6: Table S5). Several studies in temperate coastal areas showed seasonal succession and structuring of the bacterial community [39, 41, 71]. Accordingly, even if three genera were dominating for the entire year, the community structure of abalone digestive microbiota was impacted by seasonal variability (Fig. 1), and $17.6 \%$ of the biological variation of the microbiota was explained by the effect of sampling dates alone and by its combined effect with abalone characteristics and algal biochemical content. We found one study on seasonality of intestinal microbiota in a marine organism, the farmed Atlantic salmon, which showed highest number of bacteria in the gut with the highest temperature in August but a community composition that was quite stable over the year [72]. More temporal studies were done in fresh water, where several examples of seasonality of fishes' digestive microbiota could be observed either in terms of cell number or taxonomic composition [73]. In our study, however, the biochemistry of the four algae showed significant seasonal variations through the year, as tested with their content in soluble carbohydrates, dry algal matter and protein (Friedman test with post hoc test after Nemenyi, Roussel, personal communication), which had a significant effect on the digestive microbiota, explaining $5.4 \%$ of the biological variation of the microbiota (Additional file 1: Figure S4). Also, individual microbial genera of the dominant core and the less abundant microbiota were differently correlated with temporal fluctuations of contextual parameters (Fig. 5). For instance, the presence of Vibrio, Psychromonas, an unclassified Rhodobacteraceae, Polaribacter, and Pseudahrensia was positively correlated with increasing water temperature (Fig. 5). Seasonal variations have been previously described for Vibrio and Polaribacter in the plankton and in particle-attached fractions in coastal waters 
$[41,74]$, but no study could be found on seasonality in coastal waters of Psychromonas and of Pseudahrensia. Seasonal fluctuations of Vibrio and the less abundant and diet-specific core microbiota may thus be not only influenced by algal diet biochemical content but also by the seasonality of the water column composition.

\section{Establishment and potential functioning of abalone digestive microbiota}

A major factor that may explain part of the unexplained $69.2 \%$ of biological variation is microbial interactions. Following niche construction theory, microbiota play a role in modifying physicochemical conditions of the digestive gland and apply selection pressure to themselves, their descendants, and immigrating cells [75]. Here, the selection of the holobiont microbiota may result in the cooperation between degraders of algal polysaccharides and fermenters of the resulting products in microaerophilic and acidic conditions. Indeed, aerobic bacteria ingested with the diet have been shown to rapidly consume all the available oxygen in the gastrointestinal tract, providing ideal conditions for fermentation of pyruvate from algal polysaccharide degradation [36, 76]. Genomes closely related to Psychrilyobacter, Mycoplasma, and Vibrio possess enzymes for the acetate pathway, allowing pyruvate fermentation to short chain fatty acids (SCFA) for further assimilation by the host (Additional file 5: Table S4, Additional file 8, Fig. 6). As hypothesized for gut colonization of the sea squirt Ciona intestinalis [42], these dominant fermenters, may be part of a resident anaerobic biofilm within the outer mucus layer at the epithelial cell surface and benefit from the host digestive properties such as the secretion of mucinlike glycoproteins [77].

Regarding algal polysaccharide degradation in abalone digestive gland, two scenarios are possible, involving either (i) the core dominant community only, or (ii) the core dominant community together with the less abundant and the transient community (Fig. 6). The first scenario is based on putative lateral acquisitions of CAZymes by the three dominant genera of the abalone digestive microbiota, e.g., from algal epiphytic bacteria. Earlier studies have shown the possibility of horizontal transfer of CAZyme-genes (e.g., beta-porphyranases, GH117, alginate

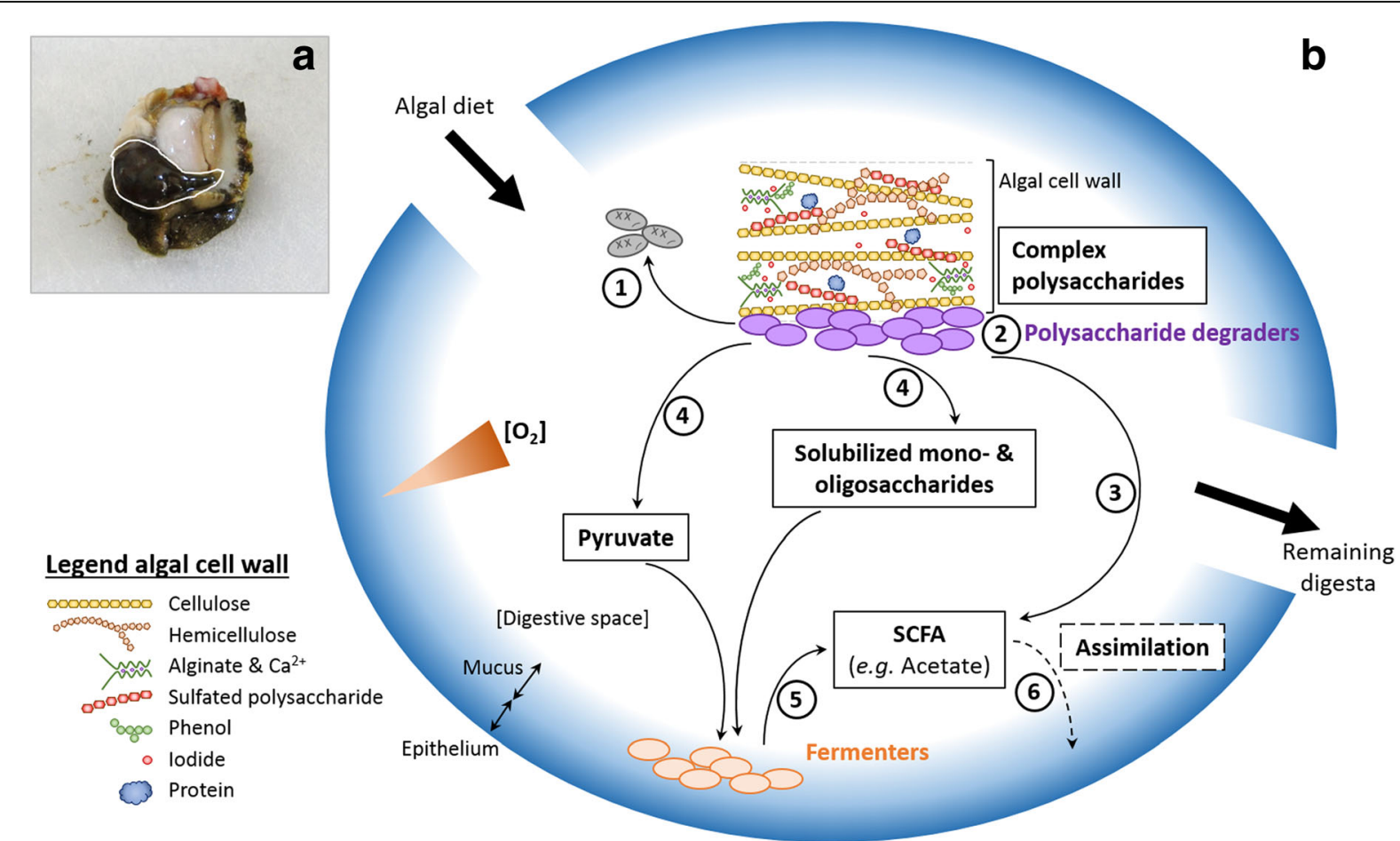

Fig. 6 Proposed processes of algal polysaccharide degradation in the abalone digestive gland. For information, localization of the abalone digestive gland on an abalone without the shell (a). The schematic illustration recapitulates hypothetical processes of algal polysaccharide degradation in the case of a brown algal cell wall (b). The algal diet comes along with epiphytic bacteria, including (1) strictly aerobic bacteria which may die due to specific physiochemical conditions (low $\mathrm{O}_{2}$, low pH) and (2) facultative aerobic bacteria, which may act as primary degraders of complex algal polysaccharides. Primary degraders may (3) directly ferment polysaccharides to short-chain fatty acids (SCFA, e.g. Vibrio) or (4) transform polysaccharides into pyruvate or solubilized mono- and oligosaccharides (members of Flavobacteriia, Alpha-, and Gammaproteobacteria). These may then be (5) fermented by strictly or facultative anaerobic bacteria (e.g. Psychrilyobacter, Mycoplasma), which are probably localized in an anaerobic or microaerophilic part of the gland, such as the epithelial mucus. Resulting SCFA are then (6) assimilated by the host. Parts of the illustration are inspired from [6, 96]. Abalone picture: courtesy of Monique Ras 
lyases) from algal epiphytic bacteria to intestinal bacteria from human or marine fishes in relation to the consumption of seaweeds [78-80]. In this scenario, the less abundant core microbiota and transient bacteria would play only a complementary role in algal degradation. The second scenario assumes that the dominant bacteria in the microbiota are largely incapable of degrading complex algal polysaccharides, as suggested by their low CAZyme and sulfatase content found in our survey. Only Vibrio may possess a limited capacity to degrade algal polysaccharides as suggested by the analysis of $V$. crassostreae and $V$. breoganii genome, which are often found in the gut of invertebrates, and genomes of the species $V$. crassostreae, $V$. harveyi, and $V$. halioticoli which were previously isolated from abalone gut and described as alginate degraders [44, 81]. Also, $V$. halioticoli isolated from abalone are able to produce SCFA such as acetate from alginate (Additional file 5: Table S4 and Additional file 8, [16, 81, 82]). The less abundant and diet-specific core microbiota may complement the capacities of Vibrio as they also have the potential to degrade algal polysaccharides, e.g., Polaribacter, Roseobacter, or Psychromonas [54, 55, 60, 81].

In either of the two scenarios, the abalone holobiont seems to provide the ideal conditions in the digestive gland to maintain a core microbiota which probably plays a major role in producing assimilable products for the abalone from complex dietary compounds such as algal polysaccharides.

\section{Conclusion}

The most striking finding here is that the abalone digestive microbiota seems to be already established during the first year of life of the abalone and that seasonal variation, feed type, and quality only account for a small proportion of the variability of the microbiota. This is in agreement with the existence of a relatively stable digestive microbiota, inherent part of the holobiont. In the case of a healthy abalone holobiont, digestive gland conditions may control the composition of the microbiota, and in return, this microbiota may be adapted to seasonal variations. In addition, transient and rare algal epiphytic bacteria may remain in the niche, depending on their ability to assist in algal polysaccharide degradation. In the abalone holobiont, two non-exclusive scenarios may occur during digestion: (i) the dominant fermenters have acquired polysaccharide degrading genes by lateral gene transfer from aerobic epiphytic algal microbiota, and degrade and ferment algal polysaccharides themselves, (ii) the aerobic epiphytic algal microbiota cooperate with the dominant fermenters to transform algal polysaccharides to SCFA. To test these hypotheses and to elucidate further details on the functional plasticity of the dominant fermenters or the aerobic microbiota, we would need to investigate microbial genes associated with abalone digestion, using metagenomic tools or trying to isolate candidates and further analyze their genomes.

Altogether, these results on a marine generalist herbivore further highlight the specificity and durability of the holobiont association, between the host and its digestive microbiota, even in an open and mixing natural environment such as seawater. A better understanding of the functioning of this marine holobiont will contribute to increase our knowledge on abalone biology and to improve natural and sustainable cultivation methods.

\section{Methods}

\section{Study site and sampling procedure}

European abalone (Haliotis tuberculata Linnaeus, 1758), marine herbivorous gastropods, were bred at the seabased abalone farm France Haliotis, on the coast of Brittany, France $\left(48^{\circ} 36^{\prime} 46 \mathrm{~N} ; 4^{\circ} 33^{\prime} 30 \mathrm{~W}\right)$. In summer 2010 , juveniles were bred on land in nursery tanks for a year before being transferred to sea-based experimental cages and fed with a mixed algal diet composed of P. palmata, S. latissima, and L. digitata for about 6 months. Abalone were then not fed for a week before the beginning of the experiment (Additional file 1: Figure S5). The experiment started in February 2012, and three abalone were randomly sampled from each cage. Abalone were then fed ad libitum every month with one of the monospecific diets: P. palmata, U. lactuca, L. digitata, S. latissima, and this was replicated in three cages for each algal treatment. About every 2 months from February 2012 to January 2013, 3 abalone were taken randomly from each of the 12 cages and the resulting 216 abalone were frozen at $-80^{\circ} \mathrm{C}$ until further analysis of the digestive bacterial microbiota (Additional file 1: Figure S6). On the same dates, additional abalone were sampled for measurements of growth and sexual maturation and the fresh algal diet was sampled before abalone feeding to subsequently analyze algal biochemical composition (see Additional file 8 for details).

DNA extraction, metabarcoding, and sequence processing As it is closely surrounded by the gonads, the digestive gland could not be separated from the gonads during dissection. The gonado-digestive gland (simplified as the digestive gland throughout the manuscript) of 216 abalone was thus dissected as a whole and was freeze-dried before tissue grinding (Additional file 1: Figure S7). DNA was extracted from ground lyophilized glands and the V3-V4 variable region of the 16S rRNA gene was amplified using primers targeting Bacteria. Amplicons from three abalone of the same conditions (same cage and same sampling date) were then pooled before MiSeq paired-end sequencing (Illumina, San Diego, CA, USA), which resulted in about 10 
million sequence reads. Sequence quality check, curation, alignment, and chimera removal were done using publicly available scripts (fastx_toolkit, http:// hannonlab.cshl.edu/fastx_toolkit/; get_paired.py, http:// abims.sb-roscoff.fr, mothur v.1.34.4, [83]). Sequences were taxonomically classified with the RDP classifier [84] on the Silva release 119 [85] and OTUs were clustered at 97\% sequence identity using the average neighbor algorithm (see Additional file 8 for details, [86]).

\section{Diversity analyses and ecological patterns of the digestive microbiota}

Shannon and Simpson indices were calculated from 1000 resamplings of the original table to the lowest number of sequence reads per sample (12,997 sequence reads). Dissimilarities in community structure were studied for all taxonomic levels using the Bray-Curtis dissimilarity index after Hellinger transformation of the data set [87]. The analysis of similarity (ANOSIM) allowed testing the grouping of samples according to sampling date, season, or algal diet.

Contextual parameters were measured in a parallel study, and the best combinations of these to explain the variation in the microbial community matrix were determined by forward selection (Additional file 8 and Roussel, personal communication). Parameters were $\log _{10}$-transformed, and the community matrix was standardized by Hellinger transformation [87]. Variation partitioning was then used on the community matrix to investigate the effects of the selected parameters (abalone characteristics, algal composition, sampling date) and of their covariation on the structure of the microbiota [88, 89].

Data analyses were performed using PAST version 2.17 [90] and the $\mathrm{R}$ version 3.2.2 programming environment as well as the vegan package and custom $\mathrm{R}$ scripts ([71], http://www.mpi-bremen.de/en/Software_4.html).

\section{Gene annotation of the core genera}

Carbohydrate active enzymes (CAZymes) and sulfatases contents from 127 genomes of the genus Vibrio, 111 genomes of Mycoplasma, 6 genomes of Polaribacter, 2 genomes of Roseobacter, and 2 genomes of Psychromonas were retrieved from the CAZY and SulfAtlas websites [32, 91-93]. No Psychrilyobacter genome was available on the CAZY website, so the Psychrilyobacter atlanticus DSM 19335 genome was downloaded from NCBI, project accession PRJNA195804 [94] as well as genomes from the fish-associated mycoplasma Mycoplasma mobile 163K [33] as an example of marine Mycoplasma and Vibrio halioticoli, project accession BAUJ00000000 [95], a Vibrio isolated from abalone [94]. CAZyme and sulfatase annotations of each sequence were performed manually by homology with sequences from the CAZy and SulfAtlas databases, from which fasta files can be downloaded, using a minimum sequence identity of $25 \%$, and a minimum query and hit coverage of $70 \%$ between amino-acid sequences. To investigate pyruvate to acetate fermentation, a database including sequences of the enzymes involved in the according pathways was manually created to further annotate genes from $P$. atlanticus, M. mobile, and $V$. halioticoli by homology, following the same conditions as for CAZyme gene annotation (for details on the pyruvate to acetate fermentation database, see Additional file 6: Table S5, Additional file 7: Table S6 and Additional file 8). Gene annotations were carried out using the ngKLAST software (ngKLAST release 4.2, 2007-2013, Korilog SARL, France).

\section{Additional files}

Additional file 1: Figure S1. Alpha-diversity of the digestive microbiota of abalone, as described by the Shannon (left panels) and Simpson (right panels) indices. Figure S2. Fluctuations of the digestive microbiota between consecutive dates over 1 year. Figure S3. Relative abundance and taxonomical composition of the digestive microbiota at the phylum level for abalone fed on Palmaria palmata (A), Laminaria digitata (B), Ulva lactuca (C), and Saccharina latissima (D). Figure S4. Ecological patterns of the digestive microbiota explained by a model of contextual parameters. Figure S5. Experimental site and set up. Figure S6. In situ sampling procedure of abalone for each algal treatment. Figure S7. Experimental procedure for DNA extraction and library preparation for studying the abalone digestive microbiota. (DOCX $1944 \mathrm{~kb}$ )

Additional file 2: Table S1. Wilcoxon test to compare Shannon or Simpson indices between algal diets for the whole data set or between sampling dates or seasons for each algal diet (multiple comparisons were corrected using FDR). (XLSX $22 \mathrm{~kb}$ )

Additional file 3: Table S2. $R$ value of the ANOSIM calculated for the whole dataset and for each algal diet dataset separately between sample groups according to season, sampling date, or algal diet. Numbers in bold indicate the significance of the comparison after Bonferroni correction. (XLSX $15 \mathrm{~kb}$ )

Additional file 4: Table S3. Number of annotated genes for each glycoside hydrolase, polysaccharide lyase, and sulfatase family in all Vibrio, Mycoplasma, Polaribacter, Roseobacter, and Psychromonas genomes available at http://www.cazy.org/ and/or at http://abims.sb-roscoff.fr/ sulfatlas/ on 19 May 2017 and in Zobellia galactanivorans DsijT (Barbeyron et al. 2017). GH, Glycoside hydrolases; PL, Polysaccharide lyases, CAZyme, Carbohydrate active enzyme. Sulfatase gene counts are indicated when available in the SulfAtlas database. (XLSX $160 \mathrm{~kb}$ )

Additional file 5: Table S4. Genes belonging to families of glycoside hydrolases, polysaccharide lyases, or sulfatases and genes putatively involved in the pyruvate fermentation to acetate pathway in the genomes of Psychrilyobacter atlanticus DSM19335 (A), Vibrio halioticoli NBRC 102217 (B), and Mycoplasma mobile $163 \mathrm{~K}(\mathrm{C})$, when present. Annotations include gene identifiers (locus tags), closest characterized homologs with their UniProtKB ID number when available, EC numbers, and information on their functioning. The percentage of amino-acid sequence identity is indicated in parentheses. (XLSX 66 kb)

Additional file 6: Table S5. Measures of abalone characteristics and algal composition from April 2012 to January 2013. See supplementary text for details. GDG, gonado-digestive gland; DG, digestive gland. (XLSX $33 \mathrm{~kb}$ )

Additional file 7: Table S6. Fasta sequences of the pyruvate to acetate formation pathways, I, II, and IV, commonly found in Bacteria according to MetaCyc (https://metacyc.org/META/NEW-IMAGE?object=SuperPathways\&detail-level=3). (DOCX 61 kb) 
Additional file 8: Supplementary text. Supplementary information on methods used and results analysed for the study. (DOCX $43 \mathrm{~kb}$ )

\section{Acknowledgements}

The authors would like to thank the team of France Haliotis, lan McKenzy-Sproat, and Xavier Lesage for the animal care and assistance during the experiment. We are grateful to all the students who have participated in algal harvesting during the feeding and sampling process. We thank Sophie Goulitquer, Tristan Barbeyron, and Philippe Potin for the helpful comments on tissue grinding and DNA extraction. We thank Frédérique Le Roux and Christian Jeanthon for providing the positive controls. We thank the guest editor Jean-Christophe Simon and two anonymous reviewers for their helpful comments on an earlier version of the manuscript. We thank the CNRS-UPMC ABiMS bioinformatics platform (http://abims.sb-roscoff.fr), the Genomer platform core facility, and the technical platform P2M2 (Metabolic Profiling and Metabolomic Platform, INRA), part of the Biogenouest metabolomics core facility Corsaire for technical support.

\section{Funding}

This work benefited from the support of the French Government via the National Research Agency investment expenditure program IDEALG (ANR-10-BTBR-04). MP, SD, GM, and $\mathrm{CL}$ acknowledge the support by the Centre National de la Recherche Scientifique (CNRS).

\section{Availability of data and materials}

Raw Illumina reads were deposited at the European Nucleotide Archive under project accession number PRJEB15713. The dataset with contextual parameters used for the calculation of the variation partitioning and the correlations is available in Additional file 6: Table S5.

\section{Authors' contributions}

$A G, C L$, and $G M$ designed the abalone digestive microbiota study. SR and SH designed the abalone experiment in situ. AG, CL, CCa, CCo SH, and SR collected abalone, algae for abalone feed and measured contextual parameters. $A G, L M$, and MP processed the samples, including abalone digestive gland dissections, DNA extractions, library preparation, and Illumina MiSeq sequencing. $A G, S D, C L$, and $G M$ analyzed and interpreted the data. AG wrote the first draft of the manuscript and SD, GM, and $\mathrm{CL}$ contributed substantially to the revisions. All authors read and approved the final manuscript.

\section{Ethics approval and consent to participate}

Not applicable.

\section{Consent for publication}

Not applicable.

\section{Competing interests}

The authors declare that they have no competing interests.

\section{Publisher's Note}

Springer Nature remains neutral with regard to jurisdictional claims in published maps and institutional affiliations.

\section{Author details}

'Sorbonne Universités, UPMC Université Paris 06, CNRS, UMR 8227, Integrative Biology of Marine Models, Station Biologique de Roscoff, CS 90074, F-29688 Roscoff Cedex, France. ${ }^{2}$ Sorbonne Universités, UPMC Université Paris 06, CNRS, FR2424, Genomer, Station Biologique de Roscoff, CS 90074, F-29688 Roscoff Cedex, France. ${ }^{3}$ LEMAR, UMR 6539, IUEM, Plouzané, France. ${ }^{4}$ France Haliotis, Plouguerneau, France.

\section{Received: 24 August 2017 Accepted: 23 January 2018}

\section{Published online: 27 March 2018}

\section{References}

1. Pitlik SD, Koren O. How holobionts get sick - toward a unifying scheme of disease. Microbiome. 2017:5:64.

2. Ley RE, Lozupone CA, Hamady M, Knight R, Gordon Jl. Worlds within worlds: evolution of the vertebrate gut microbiota. Nat. Rev. Microbiol. 2008; 6:776-88.
3. Lozupone CA, Stombaugh JI, Gordon JI, Jansson JK, Knight R. Diversity, stability and resilience of the human gut microbiota. Nature. 2012:489:220-30.

4. David $L A$, et al. Diet rapidly and reproducibly alters the human gut microbiome. Nature. 2014;505:559-63.

5. Brune A. Symbiotic digestion of lignocellulose in termite guts. Nat Rev Microbiol. 2014;12:168-80

6. Flint HJ, Bayer EA, Rincon MT, Lamed R, White BA. Polysaccharide utilization by gut bacteria: potential for new insights from genomic analysis. Nat. Rev. Microbiol. 2008;6:121-31.

7. Egan S, et al. The seaweed holobiont: understanding seaweed-bacteria interactions. FEMS Microbiol Rev. 2013;37:462-76.

8. Dittami SM, et al. Host-microbe interactions as a driver of acclimation to salinity gradients in brown algal cultures. ISME J. 2016;10:51-63.

9. Matsuo Y, Suzuki M, Kasai H, Shizuri Y, Harayama S. Isolation and phylogenetic characterization of bacteria capable of inducing differentiation in the green alga Monostroma oxyspermum. Environ Microbiol. 2003;5:25-35

10. Tapia JE, González B, Goulitquer S, Potin P, Correa JA. Microbiota influences morphology and reproduction of the brown alga Ectocarpus sp. Front Microbiol. 2016:7:1-14.

11. Wiese J, Thiel V, Nagel K, Staufenberger T, Imhoff JF. Diversity of antibioticactive bacteria associated with the brown alga Laminaria saccharina from the Baltic Sea. Mar Biotechnol. 2009;11:287-300.

12. Popper ZA, et al. Evolution and diversity of plant cell walls: from algae to flowering plants. Annu Rev Plant Biol. 2011;62:567-90.

13. Ficko-Blean E, Hervé C, Michel G. Sweet and sour sugars from the sea: the biosynthesis and remodeling of sulfated cell wall polysaccharides from marine macroalgae. Perspect Phycol. 2015;2:51-64.

14. Hehemann $J H$, Boraston AB, Czjzek M. A sweet new wave: structures and mechanisms of enzymes that digest polysaccharides from marine algae. Curr Opin Struct Biol. 2014;28:77-86.

15. Martin M, Portetelle D, Michel G, Vandenbol M. Microorganisms living on macroalgae: diversity, interactions, and biotechnological applications. App Microbiol Biotechnol. 2014;98:2917-35.

16. Martin $\mathrm{M}$, et al. The cultivable surface microbiota of the brown alga Ascophyllum nodosum is enriched in macroalgal-polysaccharide-degrading bacteria. Front Microbiol. 2015;6:1-14.

17. Burke C, Thomas T, Lewis M, Steinberg P, Kjelleberg S. Composition, uniqueness and variability of the epiphytic bacterial community of the green alga UIva australis. ISME J. 2011;5:590-600.

18. Bengtsson MM, Sjøtun K, Lanzén A, Ovreås L. Bacterial diversity in relation to secondary production and succession on surfaces of the kelp Laminaria hyperborea. ISME J. 2012;6:2188-98.

19. Lachnit T, Meske D, Wahl M, Harder T, Schmitz R. Epibacterial community patterns on marine macroalgae are host-specific but temporally variable. Environ Microbiol. 2011:13:655-65.

20. Fernandes N, Steinberg P, Rusch D, Kjelleberg S, Thomas T. Community structure and functional gene profile of bacteria on healthy and diseased thalli of the red seaweed Delisea pulchra. PLoS One. 2012;7:1-8.

21. Dudek $M$, et al. Metaphylogenomic and potential functionality of the limpet Patella pellucida's gastrointestinal tract microbiome. Int J Mol Sci. 2014;15: 18819-39.

22. Hong P-Y, Wheeler E, Cann IKO, Mackie RI. Phylogenetic analysis of the fecal microbial community in herbivorous land and marine iguanas of the Galápagos Islands using 16S rRNA-based pyrosequencing. ISME J. 2011;5:1461-70.

23. Vitalis $T$, Spence $M$, Carefoot $T$. The possible role of gut bacteria in nutrition and growth of the sea hare. Veliger. 1988;30:333-41.

24. Galli DR, Giese AC. Carbohydrate digestion in a herbivorous snail, Tegula funebralis. J Exp Zool. 1959;140:415-40.

25. Huang Z-B, Guo F, Zhao J, Li W-D, Ke C-H. Molecular analysis of the intestinal bacterial flora in cage-cultured adult small abalone, Haliotis diversicolor. Aquac Res. 2010;41:e760-9.

26. Cook PA. The worldwide abalone industry. Mod Econ. 2014:5:1181-6.

27. Leighton D, Boolootian RA. Diet and growth in the black abalone, Haliotis cracerodii. Ecol Soc Am. 1963:44:228-38.

28. Erasmus $\mathrm{JH}$, Cook PA, Coyne VE. The role of bacteria in the digestion of seaweed by the abalone Haliotis midae. Aquaculture. 1997:155:377-86.

29. Barbeyron T, et al. Habitat and taxon as driving forces of carbohydrate catabolism in marine heterotrophic bacteria: example of Zobellia galactanivorans DsijT. Environ Microbiol. 2016;0

30. Bethesda (MD): National Library of medicine (US) NC for BI. Genome [Internet]. 2004; https:/www.ncbi.nlm.nih.gov/genome/. Accessed 19th May 2017. 
31. Zhao JS, Manno D, Hawari J. Psychrilyobacter atlanticus gen. nov., sp. nov., a marine member of the phylum Fusobacteria that produces $\mathrm{H} 2$ and degrades nitramine explosives under low temperature conditions. Int J Syst Evol Microbiol. 2009:59:491-7.

32. Lombard V, Golaconda Ramulu H, Drula E, Coutinho PM \& Henrissat B. The carbohydrate-active enZYmes database. 2014; www.cazy.org. Accessed 19 May 2017.

33. Jaffe JD, et al. The complete genome and proteome of Mycoplasma mobile. Genome Res. 2004;14:1447-61.

34. Miles RJ. Review article catabolism in Mollicutes. J Gen Microbiol. 1992;138: 1773-83.

35. Thompson FL, lida T, Swings J. Biodiversity of Vibrios. Microbiol Mol Biol Rev. 2004;68:403-31.

36. Harris JO, Burke CM, Maguire GB. Characterization of the digestive tract of greenlip abalone, Haliotis laevigata Donovan. II. Microenvironment and bacterial flora. J Shellfish Res. 1998;17:989-94.

37. Gomez-Pinchetti JL, Garcia-Reina G. Enzymes from marine phycophages that degrade cell walls of seaweeds. Marine Biol. 1993;116:553-8.

38. Russell JB, Wilson DB. Why are ruminal cellulolytic bacteria unable to digest cellulose at low pH? J Dairy Sci. 1996;79:1503-9.

39. Gilbert JA, et al. The seasonal structure of microbial communities in the Western English Channel. Environ Microbiol. 2009;11:3132-9.

40. Zinger $L$, et al. Global patterns of bacterial beta-diversity in seafloor and seawater ecosystems. PLoS One. 2011;6:e24570.

41. Teeling $\mathrm{H}$, et al. Substrate-controlled succession of marine bacterioplankton populations induced by a phytoplankton bloom. Science. 2012;336:608-11.

42. Dishaw $L$, et al. The gut of geographically disparate Ciona intestinalis harbors a core microbiota. PLoS One. 2014:9:e93386.

43. Nelson TM, Rogers TL, Brown MV. The gut bacterial community of mammals from marine and terrestrial habitats. PLoS One. 2013:8:1-8.

44. Preheim SP, et al. Metapopulation structure of Vibrionaceae among coastal marine invertebrates. Environ Microbiol. 2011:13:265-75.

45. Yoshimizu M, Kimura T. Study on the intestinal microflora of salmonids. Fish Pathol. 1976;10:243-59.

46. Onarheim AM, Wiik R, Burghardt J, Stackebrandt E. Characterization and identification of two Vibrio species indigenous to the intestine of fish in Cold Sea water; description of Vibrio iliopiscarius sp. nov. Syst. Appl. Microbiol. 1994:17:370-9.

47. Laycock RA. The detrital food chain based on seaweeds. I. Bacteria associated with the surface of Laminaria fronds. Mar Biol. 1974;25:223-31.

48. Eckburg PB, et al. Diversity of the human intestinal microbial flora. Science (80-). 2005;308:1635-8.

49. Ley RE, Peterson DA, Gordon Jl. Ecological and evolutionary forces shaping microbial diversity in the human intestine. Cell. 2006;124:837-48.

50. Charrier M, Fonty G, Gaillard-Martinie B, Ainouche K, Andant G. Isolation and characterization of cultivable fermentive bacteria from the intestine of two edible snails, Helix pomatia and Cornu aspersum (Gastropoda: Pulmonata). Biol Res. 2006;39:669-81.

51. Cardoso AM, et al. Gut bacterial communities in the giant land snail Achatina fulica and their modification by sugarcane-based diet. PLoS One. 2012;7:1-6.

52. Kim YO, et al. Description of Lutimonas halocynthiae sp. nov., isolated from a golden sea squirt (Halocynthia aurantium), reclassification of Aestuariicola saemankumensis as Lutimonas saemankumensis comb. nov. and emended description of the g. Int J Syst Evol Microbiol. 2014;64:1984-90.

53. Nedashkovskaya Ol, et al. Ulvibacter litoralis gen. Nov., sp. nov., a novel member of the family Flavobacteriaceae isolated from the green alga UIva fenestrata. Int J Syst Evol Microbiol. 2004;54:119-23.

54. Xing $P$, et al. Niches of two polysaccharide-degrading Polaribacter isolates from the North Sea during a spring diatom bloom. ISME J. 2015;9:1410-22.

55. Shiba T. Roseobacter litoralis gen. nov., sp. nov., and Roseobacter denitrificans sp. nov., aerobic pink-pigmented bacteria which contain bacteriochlorophyl a. Syst Appl Microbiol. 1991;14:140-5.

56. Kim HS, et al. Pseudahrensia todarodis sp. nov., isolated from the gut of a Japanese flying squid, Todarodes pacificus. Int J Syst Evol Microbiol. 2016;66: 1389-93.

57. Hosoya S, Jang JH, Yasumoto-Hirose M, Matsuda S, Kasai H. Psychromonas agarivorans sp. nov., a novel agarolytic bacterium. Int J Syst Evol Microbiol. 2009;59:1262-6

58. Yoon J, et al. Description of Persicirhabdus sediminis gen. nov., sp. nov., Roseibacillus ishigakijimensis gen. Nov., sp. nov., Roseibacillus ponti sp. nov.,
Roseibacillus persicicus sp. nov., Luteolibacter pohnpeiensis gen. nov., sp. Int J Syst Evol Microbiol. 2008;58:998-1007.

59. Brinkhoff T, Giebel HA, Simon M. Diversity, ecology, and genomics of the Roseobacter clade: a short overview. Arch Microbiol. 2008;189:531-9.

60. Dong $\mathrm{S}$, et al. Cultivable alginate lyase-excreting bacteria associated with the arctic brown alga Laminaria. Mar Drugs. 2012;10:2481-91.

61. Staufenberger T, Thiel V, Wiese J, Imhoff JF. Phylogenetic analysis of bacteria associated with Laminaria saccharina. FEMS Microbiol Ecol. 2008;64:65-77.

62. Yang SJ, Choo YJ, Cho JC. Lutimonas vermicola gen. nov., sp. nov., a member of the family Flavobacteriaceae isolated from the marine polychaete Periserrula leucophryna. Int J Syst Evol Microbiol. 2007;57:1679-84.

63. Jung Y-T, Park S, Lee J-S, Oh T-K, Yoon J-H. Pseudahrensia aquimaris gen. nov., sp. nov., isolated from seawater. Int J Syst Evol Microbiol. 2012;62:2056-61.

64. Chun J, et al. Report on 14 unrecorded bacterial species in Korea that belong to the phyla Bacteroidetes and Deinococcus-Thermus. J Species Res. 2015;4:137-44

65. Lorenz MG, Wackernagel W. Bacterial gene transfer by natural genetic transformation in the environment. Microbiology. 1994;58:563-602.

66. Van Der Gast CJ, et al. Partitioning core and satellite taxa from within cystic fibrosis lung bacterial communities. ISME J. 2011;5:780-91.

67. Hol WHG, et al. Non-random species loss in bacterial communities reduces antifungal volatile production. Ecology. 2015;96:2042-8.

68. Jousset $A$, et al. Where less may be more: how the rare biosphere pulls ecosystems strings. ISME J. 2017; https://doi.org/10.1038/ismej.2016.174.

69. Birrien $J$, Wafar MVM, Le Corre $P$, Riso R. Nutrients and primary production in a shallow stratified ecosystem in the Iroise Sea. J Plankton Res. 1991;13: 721-42.

70. Wafar MVM, Le Corre P, Birrien JL. Nutrients and primary production in permanently well-mixed temperate coastal waters. Estuar Coast Shelf Sci. 1983:17:431-46.

71. Gobet A, et al. Diversity and dynamics of rare and of resident bacterial populations in coastal sands. ISME J. 2012;6:542-53.

72. Hovda MB, Fontanillas R, Mcgurk C, Obach A, Rosnes JT. Seasonal variations in the intestinal microbiota of farmed Atlantic salmon (Salmo salar L.). Aquac Res. 2012;43:154-9.

73. Nayak SK. Role of gastrointestinal microbiota in fish. Aquac Res. 2010;41: 1553-73.

74. Turner JW, Good B, Cole D, Lipp EK. Plankton composition and environmental factors contribute to Vibrio seasonality. ISME J. 2009;3: 1082-92.

75. Day RL, Laland KN, Odling-Smee FJ. Rethinking adaptation. Perspect Biol Med. 2003:46:80-95.

76. Cooper GM. The cell: a molecular approach. 2nd ed. Sunderland: Sinauer Associates; 2000

77. Johansson MEV, Larsson JMH, Hansson GC. The two mucus layers of colon are organized by the MUC2 mucin, whereas the outer layer is a legislator of hostmicrobial interactions. Proc Natl Acad Sci U S A. 2011;108(Suppl):4659-65.

78. Hehemann $J H$, et al. Transfer of carbohydrate-active enzymes from marine bacteria to Japanese gut microbiota. Nature. 2010:464:908-12.

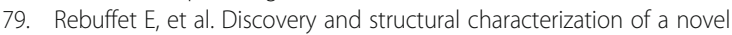
glycosidase family of marine origin. Environ Microbiol. 2011;13:1253-70.

80. Thomas F, et al. Characterization of the first alginolytic operons in a marine bacterium: from their emergence in marine Flavobacteriia to their independent transfers to marine Proteobacteria and human gut Bacteroides. Environ Microbiol. 2012;14:2379-94.

81. Tanaka $R$, et al. Temporal fluctuation in the abundance of alginate-degrading bacteria in the gut of abalone Haliotis gigantea over 1 year. Aquac Res. 2015:1-10. https://doi.org/10.1111/are.12740.

82. Sawabe $T$, et al. Acetic acid production of Vibrio halioticoli from alginate: a possible role for establishment of abalone- $V$. halioticoli association. Aquaculture. 2003;219:671-9.

83. Schloss PD, et al. Introducing mothur: open-source, platform-independent, community-supported software for describing and comparing microbial communities. Appl Environ Microbiol. 2009:75:7537-41.

84. Wang Q, Garrity GM, Tiedje JM, Cole JR. Naïve Bayesian classifier for rapid assignment of rRNA sequences into the new bacterial taxonomy. Appl Environ Microbiol. 2007;73:5261-7.

85. Quast C, et al. The SILVA ribosomal RNA gene database project: improved data processing and web-based tools. Nucleic Acids Res. 2013;41:590-6.

86. Kozich JJ, Westcott SL, Baxter NT, Highlander SK, Schloss PD. Development of a dual-index sequencing strategy and curation pipeline for analyzing 
amplicon sequence data on the MiSeq Illumina sequencing platform. Appl Environ Microbiol. 2013;79:5112-20.

87. Legendre P, Gallagher ED. Ecologically meaningful transformations for ordination of species data. Oecologia. 2001;129:271-80.

88. Borcard D, Legendre P, Drapeau P. Partialling out the spatial component of ecological variation. Ecology. 1992;73:1045-55.

89. Buttigieg PL, Ramette A. A guide to statistical analysis in microbial ecology: a community-focused, living review of multivariate data analyses. FEMS Microbiol Ecol. 2014;90:543-50.

90. Hammer $\varnothing$, Harper DAT, Ryan PD. PAST: paleontological statistics software package for education and data analysis. Palaeontol Electron. 2001:4:1-9.

91. Lombard V, Golaconda Ramulu H, Drula E, Coutinho PM, Henrissat B. The carbohydrate-active enzymes database (CAZy) in 2013. Nucleic Acids Res. 2014;42:D490-5.

92. Barbeyron T et al. SulfAtlas, the database of sulfatases. 2016; http://abims.sbroscoff.fr/sulfatlas/. Accessed 19 May 2017.

93. Barbeyron T, et al. Matching the diversity of sulfated biomolecules: creation of a classification database for sulfatases reflecting their substrate specificity. PLoS One. 2016;11:e0164846.

94. Tatusova T, Ciufo S, Fedorov B, O'Neill K, Tolstoy I. RefSeq microbial genomes database: new representation and annotation strategy. Nucleic Acids Res. 2014; 42:553-9.

95. Sawabe T, et al. Vibrio halioticoli sp. nov., a non-motile alginolytic marine bacterium isolated from the gut. Int J Syst Evol Microbiol. 1998:48:573-80.

96. Deniaud-Bouët $E$, et al. Chemical and enzymatic fractionation of cell walls from Fucales: insights into the structure of the extracellular matrix of brown algae. Ann Bot. 2014;114:1203-16.

\section{Submit your next manuscript to BioMed Central and we will help you at every step:}

- We accept pre-submission inquiries

- Our selector tool helps you to find the most relevant journal

- We provide round the clock customer support

- Convenient online submission

- Thorough peer review

- Inclusion in PubMed and all major indexing services

- Maximum visibility for your research

Submit your manuscript at www.biomedcentral.com/submit

C) Biomed Central 